Transactions of the American Fisheries Society 128:130-143, 1999

(C) Copyright by the American Fisheries Society 1999

\title{
Abundance of Gulf Sturgeon in the Apalachicola River, Florida
}

\author{
KATHERINe Potak ZehFuss \\ North Carolina Cooperative Fish and Wildlife Research Unit, Department of Zoology, \\ North Carolina State University, Raleigh, North Carolina 27695-7617, USA \\ Joseph E. HightoweR* \\ North Carolina Cooperative Fish and Wildlife Research Unit, \\ U.S. Geological Survey, Biological Resources Division, \\ Department of Zoology, North Carolina State University, Raleigh, North Carolina 27695-7617, USA \\ Kenneth H. Pollock \\ Department of Statistics, North Carolina State University, \\ Raleigh, North Carolina 27695-8203, USA
}

\begin{abstract}
Gulf sturgeon Acipenser oxyrinchus desotoi, a subspecies of Atlantic sturgeon A. oxyrinchus, were once abundant in coastal rivers of the eastern Gulf of Mexico but have declined substantially due to habitat loss and overexploitation. Because relatively little is known about their population status in the Apalachicola River, Florida, we used capture-recapture data collected during 1982-1991 to assess the population of Gulf sturgeon at the Jim Woodruff Lock and Dam, which limits upstream migration. We estimated that about 100 fish greater than $45 \mathrm{~cm}$ total length were present below the dam, although the estimates were biased to an unknown degree because of violations of capture-recapture model assumptions. To obtain a less biased estimate, we conducted an intensive 10-week capture-recapture experiment in 1993 that accounted for most of the assumption violations. We also used radiotelemetry to test the assumption that the population remained closed to immigration and emigration during sampling. The 1993 results also indicated a population of about 100 Gulf sturgeon below the dam; however, movement in and out of the sampling area occurred, so the population at the dam was not closed. Using simulation, we found that Jolly-Seber and Schnabel capture-recapture models were generally unbiased when fish had a high probability of returning to the study area after temporary emigration. However, when fish had a low probability of returning to the study area after temporary emigration, substantial bias occurred in both models. Length composition data from 1982 to 1991 and for 1993 suggested that low recruitment may account for the failure of the population to rebuild. We recommend identifying all areas of concentration of Gulf sturgeon in the Apalachicola River and developing a standardized sampling program for monitoring this threatened species.
\end{abstract}

The Gulf sturgeon Acipenser oxyrinchus desotoi is a subspecies of the Atlantic sturgeon A. oxyrinchus (Vladykov 1955; Wooley 1985). It is found in coastal rivers on the eastern Gulf of Mexico, from the lower Mississippi River eastward to the west coast of peninsular Florida as far south as Tampa Bay (Gilbert 1992). The Gulf sturgeon is anadromous; it typically uses coastal freshwater rivers from early spring through late fall and resides in the Gulf of Mexico the remainder of the year (Huff 1975; Wooley and Crateau 1982, 1985; Odenkirk 1991; Clugston et al. 1995; Carr et al. 1996; Foster and Clugston 1997).

Within the Apalachicola River, Florida, commercial Gulf sturgeon fishing began in 1899, and landings in the early 1900s ranged from about

* Corresponding author: jhightower@ncsu.edu

Received June 26, 1996 Accepted April 28, 1998
9,000 to $27,000 \mathrm{~kg}$ /year (U.S. Commission of Fish and Fisheries 1902; Huff 1975). There has been no substantial fishery since 1970 (Barkuloo 1987). Similar declines were observed throughout the Gulf of Mexico (U.S. Fish and Wildlife Service and Gulf States Marine Fisheries Commission 1995), and in 1984, the State of Florida prohibited all Gulf sturgeon fishing (Rule 46-15.01, Florida Marine Fisheries Commission). In 1991, the Gulf sturgeon was listed as a threatened species by the U.S. Fish and Wildlife Service under the U. S. Endangered Species Act.

Despite the restrictions on harvest, Gulf sturgeon populations in most rivers have not rebounded, perhaps due to reduction of spawning habitat caused by dam construction, dredging, and pollution in the rivers (Clugston et al. 1995). However, exploitation may still be a factor when Gulf sturgeon are in the Gulf of Mexico because of shrimp trawl bycatch (Wooley and Crateau 1985). 
Also, they are long-lived fish that are reported to mature late (at about 7-12 years of age) and reproduce only every 3-5 years, which decreases their recovery ability (Huff 1975).

In Florida, populations of Gulf sturgeon are still found in the Escambia, Yellow, Choctawhatchee, Apalachicola, Ochlocknee, and Suwannee rivers (Reynolds 1993). The Suwannee River is reported to have the largest and most viable population of Gulf sturgeon (Clugston et al. 1995). Carr et al. (1996) estimated that the river contained about 2,500 individuals in the $87-211-\mathrm{cm}$ range (total length, TL). Estimates of the number of Gulf sturgeon in the upper Apalachicola River for 19831988 ranged from 60 to 282 fish (Wooley and Crateau 1985; Barkuloo 1988). The estimates were for fish $75 \mathrm{~cm}$ and larger (fork length) in 1985 (when larger mesh gill nets were used) and $45 \mathrm{~cm}$ and larger in all other years (Barkuloo 1988). Estimates of population size are not available for any other Gulf of Mexico rivers.

The U.S. Fish and Wildlife Service (FWS) began tagging Gulf sturgeon in the Apalachicola River in 1978. Most sampling was conducted below the Jim Woodruff Lock and Dam (JWLD) because telemetry observations indicated that Gulf sturgeon were concentrated immediately downstream of the dam during May through September (Wooley and Crateau 1985). The objective of this study was to analyze FWS capture-recapture data collected during 1982-1991 to provide an updated series of estimates of population size and to determine whether trends in estimated abundance were present.

Our analyses of the 1982-1991 data suggested that problems with the sampling protocol probably affected the precision and accuracy of the estimates. Specific concerns included substantial differences in effort between sampling periods and between years (thus requiring a more complex model with time-variant capture probabilities), a high rate of tag loss in the early years, variation in the mesh sizes of gill nets used, and greater sampling effort in sites within the JWLD tailrace where Gulf sturgeon were previously captured. To obtain less biased estimates of population size, we conducted an intensive 10-week capture-recapture experiment in 1993. We also used ratiotelemetry to determine whether temporary emigration was occurring during the study period. Temporary emigration is movement out of and subsequently back into the study area during the study period. Little work has been done to determine the effects of temporary emigration on the precision and bias of capture-recapture models (C. Brownie, North Carolina State University, personal communication). We used simulation to evaluate the effects of temporary emigration on our population estimates, using likely scenarios for movement into and out of a sampling area and a range of capture probabilities.

\section{Study Area}

The Apalachicola River is the largest river in Florida in terms of discharge (Bass and Cox 1985). It is formed by the confluence of the Flint and Chattahoochee rivers, and the total length of the river system is about $805 \mathrm{~km}$. At the Florida, Georgia, and Alabama border (river km 171, from the mouth of the river), the Apalachicola River is impounded by the JWLD, forming Lake Seminole (Figure 1). The JWLD, which was built in 1957 , blocks the upstream migration of Gulf sturgeon and has eliminated all but $22 \%$ of their historical riverine habitat (U.S. Fish and Wildlife Service and Gulf States Marine Fisheries Commission 1995). The River and Harbor Acts of 1945 and 1946 authorized the U.S. Army Corps of Engineers to maintain a navigation channel $30.5 \mathrm{~m}$ wide and $2.7 \mathrm{~m}$ deep throughout the Apalachicola River and in the lower Flint and Chattahoochee rivers. Below Lake Seminole, much of the Apalachicola River is dredged periodically, and rock shoals have been removed (Bass and Cox 1985).

\section{Methods}

1982-1991 capture-recapture.-Although sampling began in 1978, only four Gulf sturgeon were captured before 1982, so only data from 1982 through 1991 were used for analyses. Sampling occurred on 4-16 sampling occasions from April to October of each year. Gulf sturgeon were captured with fixed monofilament and multifilament gill nets that were from 3.1 to $3.7 \mathrm{~m}$ deep and 45.7 to $91.4 \mathrm{~m}$ in length. Mesh sizes ranged from 5.1 to $30.5 \mathrm{~cm}$, and there was no established protocol regarding which nets or how many were used or where the nets were set. Set times ranged from 1.5 to $5 \mathrm{~h}$.

Upon capture, Gulf sturgeon were uniquely tagged with either a combination of two Floy tags and a Monel tag, two Floy tags and a Peterson disk tag, just Floy tags, or a Monel tag. Internal passive integrated transponder (PIT) tags were used beginning in 1991. Recapture information was always recorded, and total length and weight were measured for most fish. 


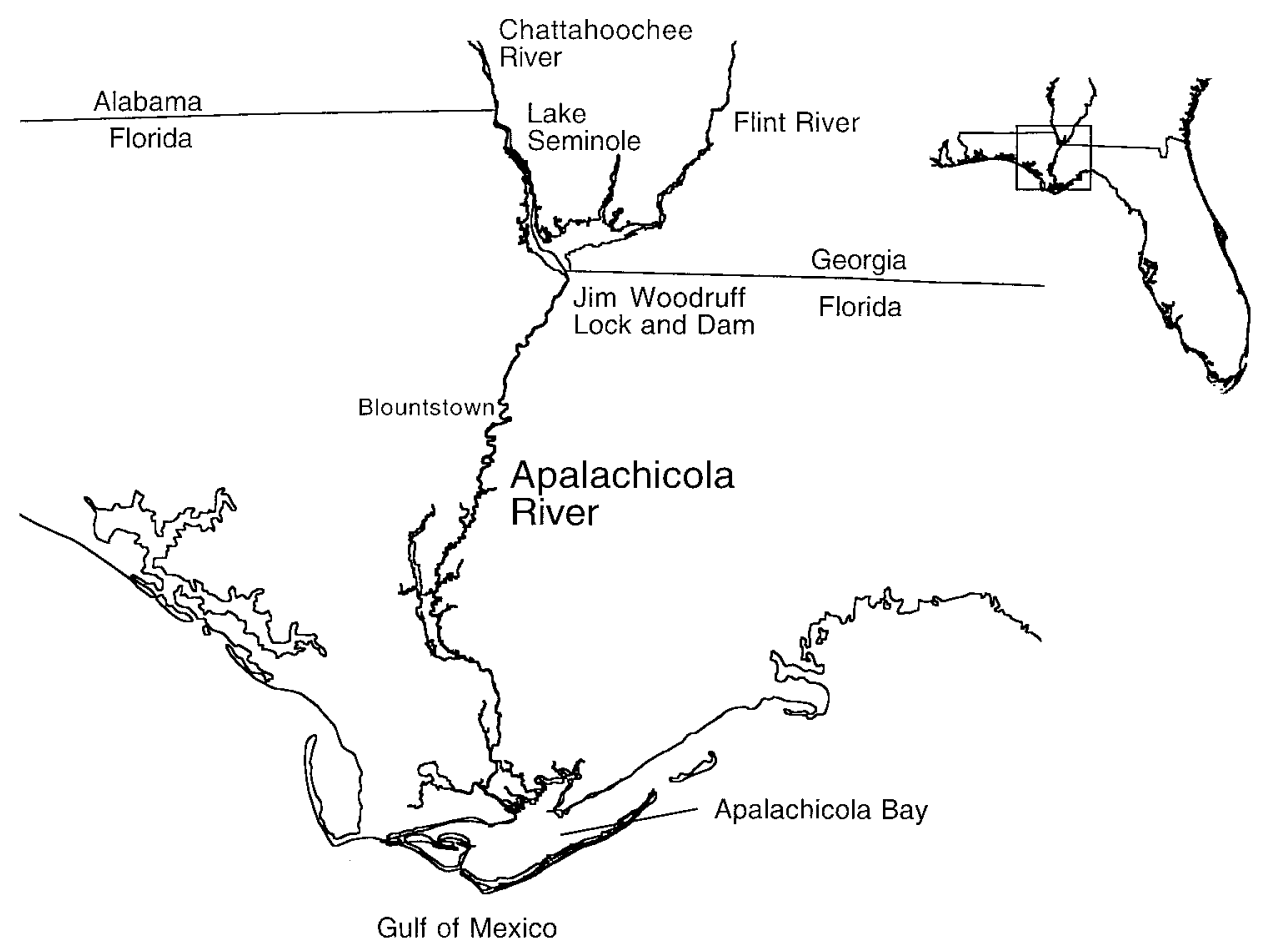

FiguRE 1.-Apalachicola River, Florida, showing location of areas studied during 1978-1993.

Following Pollock's (1982) robust design, we used closed capture-recapture models to estimate population size within each year and open models (pooled data within each year) to estimate population size and survival rate across years. The open models can account for emigration or death and immigration or recruitment that would occur over the 10-year period. The closed models can account for differences in effort or catchability among sampling occasions within each year; thus, they may yield more precise and accurate within-year population estimates than the open models (Pollock 1982). Due to the selectivity of gill nets, all population estimates apply to fish greater than $45 \mathrm{~cm}$ TL, or approximately 2 years old and older (Huff 1975).

Estimates of population size and capture probabilities within years were obtained with the program CAPTURE (Otis et al. 1978; White et al. 1982). Models from program CAPTURE can account for variability in probability of capture among sampling occasions and individual animals and for behavioral effects due to previous capture history. Model $M_{0}$ assumes that every animal in the sampled population has the same probability of capture for every sampling occasion (Pollock et al. 1990). More general models allow for het- erogeneity among individuals in capture probabilities $\left(M_{h}\right)$, a behavioral change (trap response) after first capture $\left(M_{b}\right)$, variation in capture probabilities among sampling occasions $\left(M_{t}\right)$, and various combinations of these factors. Program CAPTURE uses goodness-of-fit tests to select the simplest model that fits the data adequately (Otis et al. 1978). The objective is to achieve a balance between precision and bias. A simple model may result in a small estimated variance but biased estimates of population size. A more general model has less risk of bias, but results in estimates with larger variances. Biological information should be used when possible to guide model selection, as the goodness-of-fit tests are not independent and often have low power (Pollock et al. 1990). For a multiyear survey (as in this study), it is also useful to examine which models are selected in different years. If one model is predominately chosen, the use of estimates from that model keeps the biases constant over time so that trends can be examined.

Estimates of population size, capture probabilities, and survival rates across years were obtained using the Jolly-Seber model (Jolly 1965; Seber 1965) in program JOLLY (Pollock et al. 1990). The full Jolly-Seber model (model A) allows for variation in survival and capture probabilities from 
period to period. Where appropriate, restricted models that assume constant survival or capture probabilities can result in a large gain in precision of the estimators. Model B assumes that survival probabilities are constant over the whole experiment, model $\mathrm{C}$ assumes that capture probabilities are constant, and model $\mathrm{D}$ assumes that both survival and capture probabilities are constant. We analyzed the 1982-1991 data using model B, to account for variability in sampling effort among years. We felt that the capture-recapture data were not adequate to support annual estimates of survival, so the estimated constant rate would represent average survival during 1982-1991.

1993 capture-recapture.-Sampling occurred weekly on 10 occasions between May 25 and July 28, 1993, during daylight hours. Gulf sturgeon were caught with fixed multifilament gill nets that were $3.7 \mathrm{~m}$ deep and $45.7 \mathrm{~m}$ in length. Mesh sizes were chosen based on previous catch data: $5.1 \mathrm{~cm}$ (1 net), $12.7 \mathrm{~cm}$ (3 nets), $17.8 \mathrm{~cm}$ (4 nets), 22.9 $\mathrm{cm}$ (3 nets), and $30.5 \mathrm{~cm}$ (1 net). Set times ranged from 1.5 to $3.5 \mathrm{~h}$. The JWLD area was divided into twelve evenly spaced zones, and the 12 gill nets were randomly assigned to zones on each sampling occasion. We used two boats with crews of three persons each so that the nets could be processed rapidly to reduce the effects of gillnetting and handling on the fish.

Upon capture, Gulf sturgeon were uniquely tagged with four external Floy tags, one placed in each pectoral and pelvic fin, and one PIT tag placed in the base of the dorsal fin. Recapture information was recorded for all fish previously marked in 1993. Weight and total length measurements were taken on all sampling occasions, except one when the dam flood gates were opened during net recovery and safety was an issue.

Estimates of population size and capture probabilities, under the assumption that the population was closed, were obtained with the program CAPTURE (Otis et al. 1978). Estimates of population size and survival and capture probabilities, under the assumption that the population was open, were obtained with the program JOLLY (Pollock et al. 1990). For the open model, we used Jolly-Seber model D because survival was expected to be constant over the 10-week interval and survey effort was equal among sampling occasions.

We used ratiotelemetry to assess the appropriateness of open and closed models for this population, and to determine the magnitude of temporary emigration (Pollock et al. 1990). We fitted eight fish with external radio transmitters during the first two sampling occasions. As in earlier studies (Wooley and Crateau 1985; Odenkirk 1991; Foster and Clugston 1997), transmitters were attached with wire through the dorsal scutes. Two days after releasing the telemetered fish, we searched the JWLD area to determine whether capture and handling had caused any fish to leave the area. On each sampling occasion, before any gill nets were set, we searched the entire sampling area to determine which fish were present. After sampling, we searched for $48.4 \mathrm{~km}$ downriver for the telemetered fish not located at the JWLD. The entire Apalachicola River was searched on two sampling occasions (after initial tagging and at the completion of the study) to see if any telemetered fish had moved further than $48.4 \mathrm{~km}$ downriver.

To provide additional information about the tendancy of fish to leave the JWLD during summer, we have included results from a previous telemetry study by Odenkirk (1991). During the summer of 1987, Odenkirk attached radio transmitters to eight Gulf sturgeon collected at the JWLD, and six were relocated frequently during the summer. Odenkirk (1991) did not present the summer relocation data because the focus of the study was the upstream migration in spring and downstream migration in fall.

Discharge data for the 1987 and 1993 study periods were obtained for the JWLD from the U.S. Army Corps of Engineers. These data were used to examine whether changes in flow affected the location of radio-tagged Gulf sturgeon.

Simulations.-We simulated capture-recapture experiments conducted over 10 occasions to test the effect of temporary emigration on estimates produced by our closed and open models. Population estimates and their variances were calculated with the Jolly-Seber open model (Pollock et al. 1990: equations 4.1, 4.12) and the Schnabel closed model (Ricker 1975: equations 3.15-3.16). The Schnabel estimator (Schnabel 1938) is a less efficient approximation to the maximum likelihood model $M_{t}$ (White et al. 1982). We used the Schnabel model for the simulations because it has a closed-form solution, whereas the model $M_{t}$ must be fitted iteratively. Survival estimates and their variances were obtained from the Jolly-Seber model (Pollock et al. 1990: equations 4.2, 4.13). Population levels of 100 and 200 were assumed, based on the approximate population estimates obtained from our field studies. Capture probability was kept constant over 10 occasions and assumed to be $0.1,0.2$, or 0.5 . Survival was also kept constant and assumed to be 1.0 . 
TABLE 1.-Abundance estimates, SEs, and 95\% confidence intervals (CI) for Gulf sturgeon at the Jim Woodruff Lock and Dam made with closed and open population capture-recapture models and data from 1982 to 1991 . The closed model estimates came from program CAPTURE's model $M_{t}$, which assumes time-specific capture probabilities. The open model estimates came from program JOLLY's model $B$, which assumes time-specific capture probabilities but constant survival across years.

\begin{tabular}{|c|c|c|c|c|c|c|c|c|c|}
\hline \multirow[b]{2}{*}{ Year } & \multirow{2}{*}{$\begin{array}{l}\text { Sampling } \\
\text { occasions }\end{array}$} & \multirow{2}{*}{$\begin{array}{c}\text { Number } \\
\text { tagged }\end{array}$} & \multirow{2}{*}{$\begin{array}{l}\text { Number } \\
\text { recaptured }\end{array}$} & \multicolumn{3}{|c|}{ CAPTURE } & \multicolumn{3}{|c|}{ JOLLY } \\
\hline & & & & Estimate & SE & $95 \% \mathrm{CI}$ & Estimate & SE & $95 \% \mathrm{CI}$ \\
\hline 1982 & 4 & 28 & 0 & & & & & & \\
\hline 1983 & 12 & 75 & 24 & 149 & 22.9 & $115-208$ & 111 & 17.9 & $76-146$ \\
\hline 1984 & 12 & 38 & 10 & 87 & 21.7 & $59-150$ & 119 & 16.0 & $87-150$ \\
\hline 1985 & 16 & 71 & 43 & 101 & 9.8 & $87-127$ & 117 & 12.8 & $92-142$ \\
\hline 1986 & 14 & 34 & 12 & 65 & 13.8 & $47-105$ & 108 & 12.8 & $83-133$ \\
\hline 1987 & 13 & 39 & 7 & 116 & 36.5 & $70-225$ & 103 & 12.7 & $78-128$ \\
\hline 1988 & 16 & 54 & 17 & 109 & 20.2 & $81-164$ & 88 & 9.8 & 69-107 \\
\hline 1989 & 8 & 24 & 5 & 62 & 21.7 & $37-131$ & 91 & 15.0 & $61-120$ \\
\hline 1990 & 12 & 63 & 24 & 112 & 16.4 & $88-155$ & 218 & 52.8 & $114-321$ \\
\hline 1991 & 4 & 21 & 1 & 95 & 75.2 & $35-406$ & 144 & 31.0 & $83-205$ \\
\hline
\end{tabular}

Temporary emigration, the probability that an individual fish was absent from the study area on a given sampling occasion, was assumed to be 0.0 , 0.1 , or 0.2 . All fish were assumed to return to the study area between sampling occasions. We also simulated a lag function in temporary emigration, so that the probability of being in the study area at time $t$ depended on the fish's location at time $t$ - 1. For the lag-one model, the probability that a fish absent on occasion $t-1$ would be present on occasion $t$ was assumed to be either 0.1 or 0.9 . Five hundred capture-recapture experiments were simulated for each combination of factors (population size, capture probability, probability of temporary emigration).

The effect of temporary emigration on model estimates was assessed by comparing bias, precision, and coverage among treatment combinations. Percent relative bias was defined as

$$
\frac{(\hat{\theta}-\theta)}{\theta} \times 100,
$$

where $\hat{\theta}$ represents the estimate of model parameter $\theta$. As measures of precision, we compared the empirical and average analytical standard errors. The empirical variance was estimated directly from the 500 replicate estimates of parameter $\theta$. The average analytical variance was the average of the 500 variance estimates for individual replicates. Relative standard errors $(\%)$ were calculated as $\operatorname{SE}(\theta) / \theta \times 100$. Percent coverage refers to the percentage of replicate simulations in which the estimated $95 \%$ confidence interval for a parameter includes the true value of that parameter.

\section{Results}

\section{2-1991 Capture-Recapture}

During 1982-1991, there were 590 captures; of these, 305 were recaptures. In all, 285 Gulf sturgeon were captured, ranging in total length from 45 to $249 \mathrm{~cm}$ and ranging in weight from 0.2 to $93.0 \mathrm{~kg}$. Within a given year, number of captures ranged from 22 to 114 fish; of these, recaptures ranged from 0 to 43 fish (Table 1).

Program CAPTURE selected model $M_{o}$, which is the null model, as the most appropriate representation of our data in most years. However, the model selection process tends to be unreliable when capture probabilities are low, and a chisquare analysis of $M_{o}$ versus $M_{t}$ rejected the simpler model $M_{o}$ in $1983,1985,1987,1988,1990$, and 1991. Also, we know from field records that sampling effort varied among occasions. For those reasons, we used results from model $M_{t}$, which allows time-specific capture probabilities. The population estimates ranged from 62 to 149 Gulf sturgeon (Table 1). For the 3 years with more than 20 recaptures and more than 80 total captures (1983, 1985, and 1990), the population estimates ranged from 101 to 149 Gulf sturgeon. There were no recaptures in 1982, so no estimate is available for that year. Estimated capture probabilities for sampling occasions within each year ranged from 0.01 to 0.22 .

Our estimates of population size from the JollySeber model ranged from 88 to 218 Gulf sturgeon (Table 1), with an estimated annual survival rate of $0.67(\mathrm{SE}=0.028)$. Estimates of population size should be more reliable for the middle years (Gilbert 1973), and our estimates from 1985 to 1988 
TABLE 2.-Estimates of population size, SE, and 95\% confidence intervals (CI) for Gulf sturgeon at the Jim Woodruff Lock and Dam made with closed capture-recapture models and data from the 10-week 1993 capture-recapture study. The model selection criterion is a relative measure of how well each model fitted the data.

\begin{tabular}{lcrcc}
\hline Model & $\begin{array}{c}\text { Population } \\
\text { estimate }\end{array}$ & SE & CI & $\begin{array}{c}\text { Model } \\
\text { selection } \\
\text { criterion }\end{array}$ \\
\hline$M_{o}$ & 98 & 14.55 & $77-137$ & 0.29 \\
$M_{h}$ & 171 & 29.47 & $126-244$ & 0.20 \\
$M_{b}$ & 64 & 5.30 & $58-83$ & 0.97 \\
$M_{b h}$ & 64 & 5.30 & $58-83$ & 0.63 \\
$M_{t}$ & 96 & 13.75 & $77-133$ & 0.00 \\
$M_{t h}$ & 147 & 37.23 & $98-253$ & 1.00 \\
$M_{t b}$ & 88 & 64.46 & $59-447$ & 0.83 \\
\hline
\end{tabular}

ranged from 88 to 117 . Capture probabilities for each pooled year were between 0.15 and 0.68 .

There was no obvious pattern in the differences between population estimates produced by the open and closed models. The Jolly-Seber estimate for 1990 was considerably higher than the closed model estimate, but Jolly-Seber estimates near the end of a study typically have low reliability. Neither the closed nor open models showed a trend in population size over time.

\section{Capture-Recapture}

In all, 57 Gulf sturgeon were captured, ranging in total length from 48 to $236 \mathrm{~cm}$ and ranging in weight from 0.5 to $70.3 \mathrm{~kg}$. There were 81 total captures; of these, 22 were recaptures. All fish were released upon capture; there were no deaths due to capture or handling.

Goodness-of-fit tests indicated that capture probabilities varied among individuals and sampling occasions. Estimates from the models judged to be most appropriate $\left(M_{t h}, M_{b}, M_{t b}, M_{b h}\right)$ ranged from 64 to 147 Gulf sturgeon (Table 2). All closed models estimated the probability of capture to be less than 0.10 on each sampling occasion. Our estimates of population size from the Jolly-Seber model were less than 100 fish on each sampling occasion, with an estimated weekly survival rate of $0.79(\mathrm{SE}=0.061)$ and a capture probability of 0.16 (Table 3).

\section{Length Composition Data}

We examined population size structure by comparing length frequencies of Gulf sturgeon captured during each year (Figure 2). Due to the differences in gill-net mesh sizes used among sampling occasions and years, we included only those fish collected from 17.8, 20.3, 22.9, and 25.4-cm-
TABLE 3.-Abundance estimates, SEs, and 95\% confidence intervals (CI) for Gulf sturgeon at the Jim Woodruff Lock and Dam made with Jolly-Seber model D and data from the 10-week 1993 capture-recapture study.

\begin{tabular}{cccc}
\hline $\begin{array}{c}\text { Sampling } \\
\text { occasion }\end{array}$ & $\begin{array}{c}\text { Population } \\
\text { size }\end{array}$ & SE & $95 \%$ CI \\
\hline 2 & 77 & 25.5 & $27-127$ \\
3 & 65 & 20.7 & $25-106$ \\
4 & 66 & 21.2 & $24-107$ \\
5 & 45 & 17.0 & $12-78$ \\
6 & 39 & 15.2 & $10-69$ \\
7 & 34 & 13.4 & $8-61$ \\
8 & 21 & 9.0 & $3-39$ \\
9 & 50 & 18.8 & $13-87$ \\
10 & 19 & 11.6 & $-4-41$ \\
Mean & 46 & 35.3 & $-23-115$ \\
\hline
\end{tabular}

mesh nets, which were used consistently over the 10 years. Because length was not always recorded, sample sizes for the frequency distributions were small. We also included length composition data from 1993, using fish collected from 17.8 and 22.9cm-mesh gill nets.

Our examination of the length composition data suggested that the population might have been dominated by one mode that increased by about $10 \mathrm{~cm} /$ year. There was little evidence that younger, smaller fish were recruiting into the population until 1990, when some small fish $(<110 \mathrm{~cm} \mathrm{TL})$ were caught. This mode of recruits appears to be present in the 1991 and 1993 length distributions as well.

\section{Telemetry}

The Gulf sturgeon that Odenkirk (1991) equipped with radio tags during the summer of 1987 showed a strong tendency to remain at the JWLD (Figure 3). One fish temporarily emigrated in September; all other tagged fish were found immediately below the dam until the out-migration in October. Changes in discharge were gradual during the period when most telemetered fish were at large.

During 1993, we equipped seven Gulf sturgeon with radio transmitters on occasion 1 , and one on occasion 2. Two days after applying the radio tags, all telemetered fish were relocated in the study area. Three fish were not found after occasion 2 , one of which was recaptured on occasion 5 with its transmitter broken in half. The other two transmitters may have failed, as neither fish was found when the entire Apalachicola River was searched. Therefore, we limit our analysis to the five remaining fish that were found on almost every sampling occasion. 

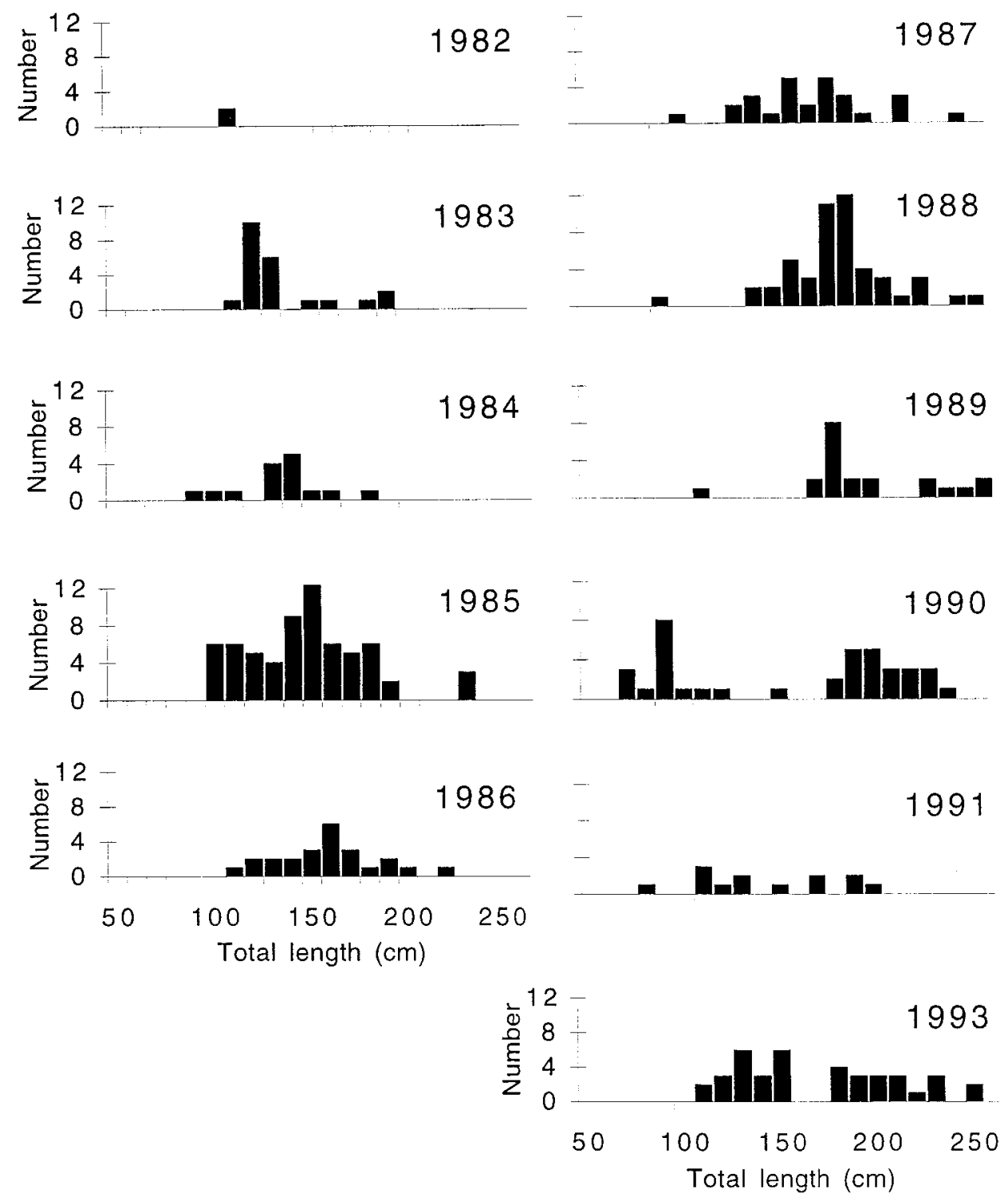

FIGURE 2.-Frequencies of total lengths of Gulf sturgeon captured in 17.8, 20.3, 22.9, and 25.4-cm-mesh gill nets during 1982-1991. For 1993, only fish captured in the 17.8 and 22.9 -cm-mesh gill nets were included.

Our 1993 telemetry results demonstrated that Gulf sturgeon did temporarily emigrate from the study area (Figure 3). Three of the five fish migrated from the study area and stayed away for at least one sampling occasion before returning. One stayed away for more than one occasion before returning; another fish returned once and then permanently emigrated from the study area. Movement away from the JWLD by three fish in midJune may have been related to a marked change in discharge, although we did not observe temporary emigration in response to a change in discharge in early July.

\section{Simulations}

Estimates of population size obtained from Schnabel's method were relatively precise and unbiased, even when temporary emigration was occurring (Table 4). For the model with no lag, the precision of population estimates decreased as the 
GULF STURGEON ABUNDANCE
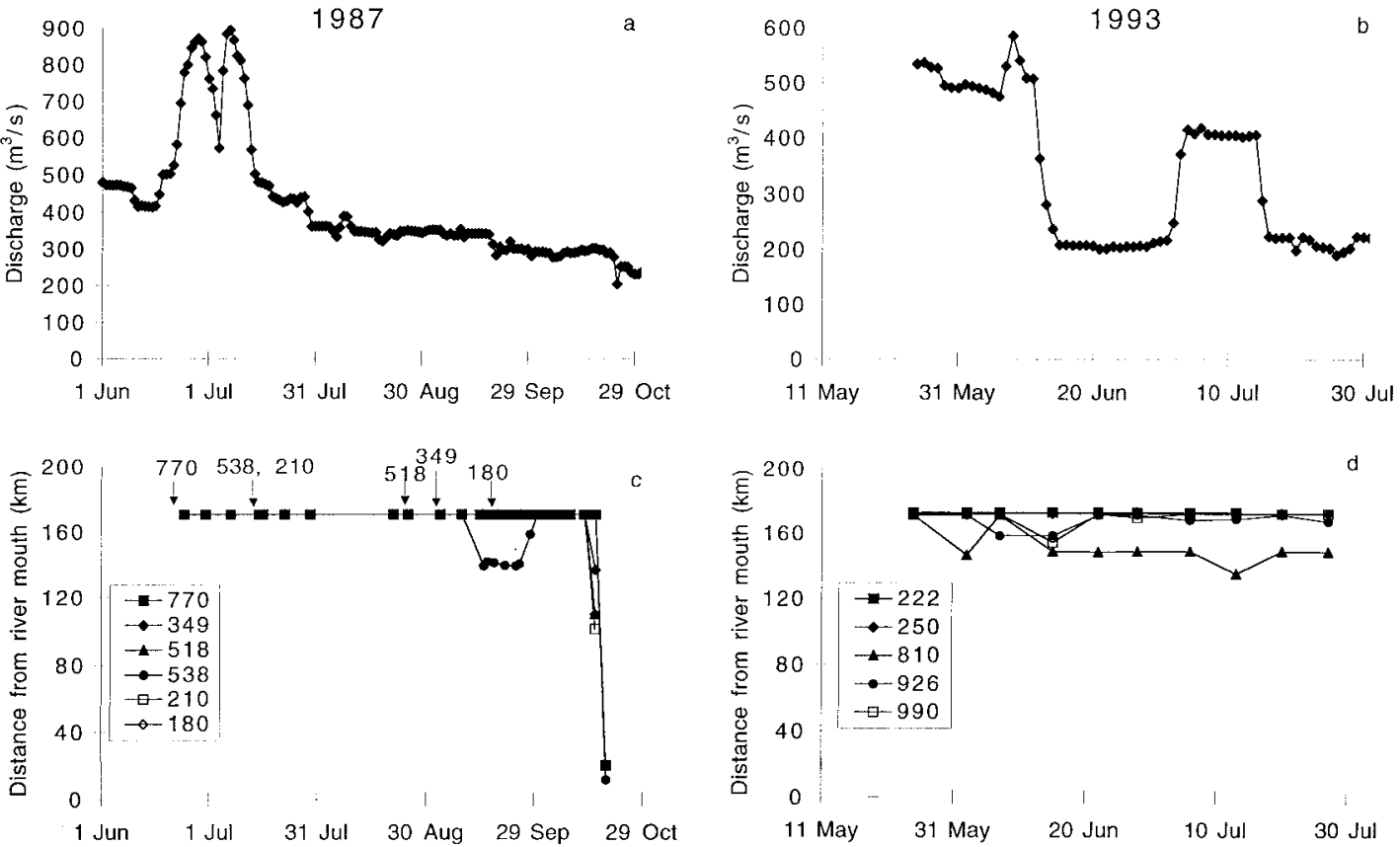

FiguRE 3.- (a, b) Discharge from the Jim Woodruff Lock and Dam (JWLD, at river km 171 from the mouth of the river) and locations of radiotagged Gulf sturgeon during the summers of (c) 1987 and (d) 1993. Each symbol in panels c and d represents an individual Gulf sturgeon. The 1987 telemetry data in panel c were collected by Odenkirk (1991); arrows indicate release dates.

TABLE 4.-Results from simulated 10-occasion capture-recapture experiments, with a constant probability of temporary emigration (being absent during a sampling occasion). Estimates were obtained with Schnabel's closed-population model.

\begin{tabular}{|c|c|c|c|c|c|c|c|c|}
\hline $\begin{array}{c}\text { Capture } \\
\text { probability }\end{array}$ & $\begin{array}{l}\text { Temporary } \\
\text { emigration } \\
\text { probability }\end{array}$ & $\begin{array}{l}\text { Average } \\
\text { estimated } \\
\text { population } \\
\text { size }(N)\end{array}$ & $\begin{array}{c}\text { Average } \\
\text { analytical } \\
\mathrm{SE}(1 / N)\end{array}$ & $\begin{array}{c}\text { Relative } \\
\text { analytical } \\
\operatorname{SE}(1 / N ; \%)\end{array}$ & $\begin{array}{c}\text { Empirical } \\
\mathrm{SE}(N)\end{array}$ & $\begin{array}{l}\text { Relative } \\
\text { empirical } \\
\mathrm{SE}(N ; \%)\end{array}$ & $\begin{array}{l}\text { Relative } \\
\text { bias (\%) }\end{array}$ & $\begin{array}{l}\text { Coverage } \\
\text { of } N(\%)\end{array}$ \\
\hline \multicolumn{9}{|c|}{ True population size: 200} \\
\hline 0.5 & 0.0 & 200 & $1.77 \mathrm{E}-04$ & 3.5 & 1.3 & 0.6 & 0.1 & 100 \\
\hline 0.5 & 0.1 & 200 & $1.89 \mathrm{E}-04$ & 3.8 & 1.8 & 0.9 & 0.0 & 100 \\
\hline 0.5 & 0.2 & 200 & $2.04 \mathrm{E}-04$ & 4.1 & 2.1 & 1.1 & -0.1 & 100 \\
\hline 0.2 & 0.0 & 201 & 3.36E-04 & 6.7 & 6.5 & 3.2 & 0.3 & 100 \\
\hline 0.2 & 0.1 & 200 & 3.67E-04 & 7.3 & 8.0 & 4.0 & -0.1 & 100 \\
\hline 0.2 & 0.2 & 200 & 4.05E-04 & 8.1 & 9.3 & 4.6 & 0.0 & 100 \\
\hline 0.1 & 0.0 & 202 & $6.03 \mathrm{E}-04$ & 12.1 & 15.6 & 7.8 & 0.8 & 100 \\
\hline 0.1 & 0.1 & 200 & $6.69 \mathrm{E}-04$ & 13.4 & 19.3 & 9.7 & -0.1 & 99 \\
\hline 0.1 & 0.2 & 203 & 7.38E-04 & 14.8 & 23.4 & 11.5 & 1.4 & 99 \\
\hline \multicolumn{9}{|c|}{ True population size: 100} \\
\hline 0.5 & 0.0 & 100 & 5.01E-04 & 5.0 & 0.9 & 0.9 & 0.0 & 100 \\
\hline 0.5 & 0.1 & 100 & $5.35 \mathrm{E}-04$ & 5.3 & 1.2 & 1.2 & 0.0 & 100 \\
\hline 0.5 & 0.2 & 100 & $5.78 \mathrm{E}-04$ & 5.8 & 1.5 & 1.5 & -0.1 & 100 \\
\hline 0.2 & 0.0 & 100 & $9.54 \mathrm{E}-04$ & 9.5 & 4.7 & 4.7 & 0.0 & 100 \\
\hline 0.2 & 0.1 & 100 & $1.04 \mathrm{E}-03$ & 10.4 & 5.5 & 5.5 & -0.1 & 100 \\
\hline 0.2 & 0.2 & 100 & $1.15 \mathrm{E}-03$ & 11.5 & 6.6 & 6.6 & -0.1 & 100 \\
\hline 0.1 & 0.0 & 101 & $1.74 \mathrm{E}-03$ & 17.4 & 12.3 & 12.3 & 0.7 & 99 \\
\hline 0.1 & 0.1 & 102 & $1.89 \mathrm{E}-03$ & 18.9 & 14.4 & 14.2 & 1.6 & 99 \\
\hline 0.1 & 0.2 & 102 & $2.12 \mathrm{E}-03$ & 21.2 & 16.4 & 16.0 & 2.0 & 98 \\
\hline
\end{tabular}


TABLE 5.-Results from simulated 10-occasion capture-recapture experiments with temporary emigration based on a lag-one model (the probability of being in the study area at time $t$ depended on the fish's location at time $t-1$ ). Estimates were obtained with Schnabel's closed-population model.

\begin{tabular}{|c|c|c|c|c|c|c|c|c|c|}
\hline $\begin{array}{c}\text { Capture } \\
\text { probability }\end{array}$ & $\begin{array}{l}\text { Temporary } \\
\text { emigration } \\
\text { probability }\end{array}$ & $\begin{array}{l}\text { Probability of } \\
\text { staying away }\end{array}$ & $\begin{array}{c}\text { Average } \\
\text { estimated } \\
\text { population } \\
\text { size }(N)\end{array}$ & $\begin{array}{c}\text { Average } \\
\text { analytical } \\
\text { SE }(1 / N)\end{array}$ & $\begin{array}{c}\text { Relative } \\
\text { analytical } \\
\mathrm{SE}(1 / N ; \%)\end{array}$ & $\begin{array}{c}\text { Empirical } \\
\operatorname{SE}(N)\end{array}$ & $\begin{array}{c}\text { Relative } \\
\text { empirical } \\
\mathrm{SE}(N ; \%)\end{array}$ & $\begin{array}{l}\text { Relative } \\
\text { bias (\%) }\end{array}$ & $\begin{array}{l}\text { Coverage } \\
\text { of } N(\%)\end{array}$ \\
\hline \multicolumn{10}{|c|}{ True population size: 200} \\
\hline 0.5 & 0.1 & 0.1 & 200 & $1.89 \mathrm{E}-04$ & 3.8 & 1.8 & 0.9 & 0.0 & 100 \\
\hline 0.5 & 0.1 & 0.9 & 181 & $2.49 \mathrm{E}-04$ & 5.0 & 4.8 & 2.7 & -9.5 & 39 \\
\hline 0.5 & 0.2 & 0.1 & 201 & 2.01E-04 & 4.0 & 2.2 & 1.1 & 0.3 & 100 \\
\hline 0.5 & 0.2 & 0.9 & 167 & $3.36 \mathrm{E}-04$ & 6.7 & 6.1 & 3.6 & -16.3 & 4 \\
\hline 0.2 & 0.1 & 0.1 & 200 & $3.66 \mathrm{E}-04$ & 7.3 & 8.1 & 4.1 & 0.1 & 100 \\
\hline 0.2 & 0.1 & 0.9 & 174 & $5.12 \mathrm{E}-04$ & 10.2 & 10.1 & 5.8 & -13.2 & 75 \\
\hline 0.2 & 0.2 & 0.1 & 201 & $3.96 \mathrm{E}-04$ & 7.9 & 9.2 & 4.6 & 0.5 & 100 \\
\hline 0.2 & 0.2 & 0.9 & 158 & 7.24E-04 & 14.5 & 13.0 & 8.2 & -20.8 & 53 \\
\hline 0.1 & 0.1 & 0.1 & 203 & $6.63 \mathrm{E}-04$ & 13.3 & 19.1 & 9.4 & 1.4 & 99 \\
\hline 0.1 & 0.1 & 0.9 & 172 & $9.52 \mathrm{E}-04$ & 19.0 & 23.2 & 13.4 & -13.8 & 95 \\
\hline 0.1 & 0.2 & 0.1 & 204 & 7.20E-04 & 14.4 & 22.6 & 11.1 & 2.2 & 99 \\
\hline 0.1 & 0.2 & 0.9 & 157 & $1.39 \mathrm{E}-03$ & 27.8 & 29.2 & 18.6 & -21.3 & 88 \\
\hline \multicolumn{10}{|c|}{ True population size: 100} \\
\hline 0.5 & 0.1 & 0.1 & 100 & $5.35 \mathrm{E}-04$ & 5.3 & 1.2 & 1.2 & 0.0 & 100 \\
\hline 0.5 & 0.1 & 0.9 & 91 & 7.04E-04 & 7.0 & 3.4 & 3.7 & -9.2 & 83 \\
\hline 0.5 & 0.2 & 0.1 & 100 & 5.69E-04 & 5.7 & 1.5 & 1.5 & 0.2 & 100 \\
\hline 0.5 & 0.2 & 0.9 & 83 & $9.60 \mathrm{E}-04$ & 9.6 & 4.4 & 5.3 & -16.5 & 42 \\
\hline 0.2 & 0.1 & 0.1 & 100 & $1.04 \mathrm{E}-03$ & 10.4 & 5.6 & 5.6 & 0.0 & 100 \\
\hline 0.2 & 0.1 & 0.9 & 86 & $1.47 \mathrm{E}-03$ & 14.7 & 7.0 & 8.2 & -13.8 & 93 \\
\hline 0.2 & 0.2 & 0.1 & 101 & $1.12 \mathrm{E}-03$ & 11.2 & 6.8 & 6.8 & 0.8 & 100 \\
\hline 0.2 & 0.2 & 0.9 & 79 & $2.10 \mathrm{E}-03$ & 21.0 & 9.5 & 12.1 & -21.1 & 83 \\
\hline 0.1 & 0.1 & 0.1 & 101 & $1.90 \mathrm{E}-03$ & 19.0 & 13.5 & 13.3 & 1.2 & 99 \\
\hline 0.1 & 0.1 & 0.9 & 88 & $2.71 \mathrm{E}-03$ & 27.1 & 16.8 & 19.1 & -12.1 & 98 \\
\hline 0.1 & 0.2 & 0.1 & 102 & $2.08 \mathrm{E}-03$ & 20.8 & 16.6 & 16.3 & 1.6 & 99 \\
\hline 0.1 & 0.2 & 0.9 & 80 & $4.12 \mathrm{E}-03$ & 41.2 & 24.7 & 30.9 & -20.0 & 95 \\
\hline
\end{tabular}

capture probability decreased or the probability of temporary emigration increased. Coverage exceeded the nominal $(95 \%)$ level in all cases. For the model of lag one, as the probability of staying away increased, the precision of the estimates decreased, a substantial negative bias occurred, and coverage decreased markedly, especially for the higher population level (Table 5).

For the Jolly-Seber model, we have presented results from the middle (fifth) sampling occasion because those estimates should be the least biased and most precise (Gilbert 1973). We found that estimates of population size were essentially unbiased, even when temporary emigration was occurring, except when $N=100$ and a low capture probability was assumed (Table 6). There was no detectable bias in the estimated survival rate due to temporary emigration. Increasing temporary emigration or decreasing the capture probability resulted in substantially lower precision for the estimates of population size or survival. Coverage was slightly less than the nominal value of $95 \%$ with no temporary emigration and declined further as capture probability decreased or temporary em- igration increased. The average analytical standard errors for the population size and survival estimates were similar to the empirical standard errors, which indicates good performance of the variance estimators.

For the model of temporary emigration with a lag of one (Table 7), we obtained the same results from the Jolly-Seber model as from the no-lag model when the probability of remaining outside the study area was low. However, as we increased the probability of staying away, the precision of the population and survival estimates decreased and there was a substantial increase in negative bias of the population estimate and decrease in coverage. The Jolly-Seber model appeared to account for the net movement out of the study area by reducing both the estimated population size and survival estimates.

\section{Discussion}

\section{Population Estimation}

Based on our results from 1993 and from past years with reasonably high numbers of captures 
and recaptures, we estimate that about 100 Gulf sturgeon greater than $45 \mathrm{~cm}$ TL occur at the JWLD in the Apalachicola River. Our estimates for the period 1983-1988 using CAPTURE model $M_{t}$ were similar to earlier Schnabel estimates (Wooley and Crateau 1985; Barkuloo 1988), except for 1983. The difference in 1983 estimates apparently results from how recaptures were counted. Wooley and Crateau (1985) did not include as recaptures fish with radio transmitters attached (due to concerns about differential vulnerability) or fish first tagged in 1982 but captured more than once in 1983 (we considered those fish to be marked after the first 1983 capture).

Our Jolly-Seber model estimates for 1993 were generally less than 75 Gulf sturgeon and declined over the course of the summer. We suspect that temporary emigration negatively biased those results. Although the fish radio-tagged by Odenkirk (1991) and Wooley and Crateau (1985) were consistently found below the dam, our telemetry results suggested that both temporary and permanent emigration occurred during our 1993 study period. In addition, our Jolly-Seber estimate of the weekly survival rate during 1993 (0.79) seems highly unlikely for such a long-lived fish, and probably is indicative of fish leaving the area.

The length composition data suggest that recruitment into the population is an infrequent event. Poor recruitment, coupled with a low estimated annual survival rate $(0.67$, based on the 1982-1991 data), could account for the failure of the population to rebuild. However, additional work is needed to establish the degree to which tag loss is responsible for the low estimated survival rate. Tag loss would, on average, cause the survival rate to be underestimated, but should not produce a bias in our estimates of population size from the Jolly-Seber model (Arnason and Mills 1981). For closed models, tag loss will cause population size to be overestimated (Otis et al. 1978).

\section{Temporary Emigration}

A key assumption of the Jolly-Seber model is that tagged fish do not migrate outside the study area and then return during the course of sampling; all emigration must be permanent (Pollock et al. 1990). Although work has been done to determine the effect of temporary emigration on survival estimates and to estimate the level of temporary emigration occurring (Balser 1981; Kendall and Nichols 1995; Kendall et al. 1997), its effect on population estimates has not been examined. Arnason and Baniuk (1978) provide a means for simulating temporary emigration in their program POPAN-2, but do not discuss its effect on estimates. No studies have been done to examine the effects of temporary emigration on closed models.

Our simulation results showed that unbiased estimates of population size can be obtained from a capture-recapture experiment even though temporary emigration is occurring. The degree to which temporary emigration introduces bias depends on whether the probability of being in the study area at time $t$ depended on the fish's location at time $t-1$. When the probability of being absent is constant, temporary emigration simply reduces capture probabilities so that estimates are less precise. However, when fish that migrate out are assumed to have a low probability of returning to the area, estimates of population size can be substantially below the true total.

Earlier studies (Wooley and Crateau 1985; Odenkirk 1991) suggested that Gulf sturgeon tagged at the JWLD remained immediately downstream of the dam during summer. The degree of temporary emigration from that area may differ from year to year, however, because our telemetry results for 1993 showed that radio-tagged Gulf sturgeon moved in and out of the study area during the first 5 weeks of the 10-week sampling period. Although sample sizes were small, we assume that temporary emigration was also occurring among untagged fish. Because no existing capture-recapture model can account for temporary emigration, we will use the simulation results to better interpret the estimates from the existing models. Ideally, we would have a larger sample size of radio-tagged fish to estimate rates of movement into and out of the study area.

During our 1993 study, about $75 \%$ of our relocations of telemetered fish were within the study area. There also seems to be a tendency for emigrating fish to stay away for at least one sampling occasion. Our field results indicate a population of about 100 fish and an estimated capture probability of less than 0.1 . Our simulation results for $N=$ 100 and capture probability of 0.1 suggest that our population estimates from the Jolly-Seber model could be negatively biased by up to $65 \%$. The coverage results for the Jolly-Seber model indicate that our estimated variances are likely to be too small and would overstate the reliability of the estimates. Based on the simulation results for Schnabel's model, our population estimate from the maximum likelihood version $\left(\operatorname{model} M_{t}\right.$ ) may be negatively biased by up to $20 \%$.

One approach for improving our estimates of 
TABLE 6.-Results from simulated 10-occasion capture-recapture experiments with a constant probability of temporary emigration (being absent during a sampling occasion). Estimates were obtained with the Jolly-Seber model and are presented for sampling occasion 5 .

\begin{tabular}{|c|c|c|c|c|c|c|c|c|}
\hline $\begin{array}{c}\text { Capture } \\
\text { probability }\end{array}$ & $\begin{array}{l}\text { Temporary } \\
\text { emigration } \\
\text { probability }\end{array}$ & $\begin{array}{c}\text { Average } \\
\text { estimated } \\
\text { population } \\
\text { size }(N)\end{array}$ & $\begin{array}{c}\text { Average } \\
\text { analytical } \\
\mathrm{SE}(N)\end{array}$ & $\begin{array}{c}\text { Relative } \\
\text { analytical } \\
\mathrm{SE}(N ; \%)\end{array}$ & $\begin{array}{c}\text { Empirical } \\
\mathrm{SE}(N)\end{array}$ & $\begin{array}{c}\text { Relative } \\
\text { empirical } \\
\text { SE }(N ; \%)\end{array}$ & $\begin{array}{c}\text { Percent } \\
\text { relative bias } \\
(N)\end{array}$ & $\begin{array}{c}\text { Percent } \\
\text { coverage } \\
(N)\end{array}$ \\
\hline \multicolumn{9}{|c|}{ True population size: 200} \\
\hline 0.5 & 0.0 & 201 & 4.7 & 2.3 & 4.9 & 2.5 & 0.4 & 91 \\
\hline 0.5 & 0.1 & 200 & 6.3 & 3.2 & 6.1 & 3.1 & 0.0 & 94 \\
\hline 0.5 & 0.2 & 200 & 8.6 & 4.3 & 8.4 & 4.2 & -0.2 & 94 \\
\hline 0.2 & 0.0 & 200 & 34.2 & 17.1 & 30.8 & 15.4 & 0.2 & 94 \\
\hline 0.2 & 0.1 & 194 & 39.2 & 20.2 & 36.2 & 18.6 & -2.8 & 90 \\
\hline 0.2 & 0.2 & 198 & 49.6 & 25.1 & 43.2 & 21.8 & -1.0 & 92 \\
\hline 0.1 & 0.0 & 203 & 117.0 & 57.6 & 85.2 & 41.9 & 1.6 & 87 \\
\hline 0.1 & 0.1 & 194 & 142.7 & 73.5 & 106.9 & 55.1 & -2.9 & 83 \\
\hline 0.1 & 0.2 & 204 & 182.4 & 89.3 & 147.5 & 72.2 & 2.2 & 85 \\
\hline \multicolumn{9}{|c|}{ True population size: 100} \\
\hline 0.5 & 0.0 & 100 & 3.3 & 3.3 & 3.3 & 3.3 & 0.2 & 92 \\
\hline 0.5 & 0.1 & 100 & 4.5 & 4.5 & 4.2 & 4.2 & -0.1 & 93 \\
\hline 0.5 & 0.2 & 100 & 6.3 & 6.3 & 6.1 & 6.1 & -0.4 & 92 \\
\hline 0.2 & 0.0 & 99 & 26.1 & 26.3 & 22.9 & 23.1 & -0.9 & 90 \\
\hline 0.2 & 0.1 & 98 & 37.8 & 38.4 & 29.7 & 30.2 & -1.6 & 89 \\
\hline 0.2 & 0.2 & 99 & 44.7 & 45.0 & 35.9 & 36.2 & -0.8 & 87 \\
\hline 0.1 & 0.0 & 91 & 74.4 & 81.3 & 55.3 & 60.5 & -8.5 & 77 \\
\hline 0.1 & 0.1 & 98 & 87.6 & 89.2 & 77.1 & 78.5 & -1.7 & 70 \\
\hline 0.1 & 0.2 & 90 & 87.8 & 98.0 & 71.5 & 79.8 & -10.5 & 62 \\
\hline
\end{tabular}

TABLE 7.- Results from simulated 10-occasion capture-recapture experiments with temporary emigration based on a lag-one model (the probability of being in the study area at time $t$ depended on the fish's location at time $t-1$ ). Estimates were obtained with the Jolly-Seber model and are presented for sampling occasion 5.

\begin{tabular}{|c|c|c|c|c|c|c|c|c|c|}
\hline $\begin{array}{c}\text { Capture } \\
\text { probability }\end{array}$ & $\begin{array}{l}\text { Temporary } \\
\text { emigration } \\
\text { probability }\end{array}$ & $\begin{array}{c}\text { Probability } \\
\text { of staying } \\
\text { away }\end{array}$ & $\begin{array}{c}\text { Average } \\
\text { estimated } \\
\text { population } \\
\text { size }(N)\end{array}$ & $\begin{array}{c}\text { Average } \\
\text { analytical } \\
\mathrm{SE}(N)\end{array}$ & $\begin{array}{c}\text { Relative } \\
\text { analytical } \\
\mathrm{SE}(N ; \%)\end{array}$ & $\begin{array}{l}\text { Empirical } \\
\operatorname{SE}(N)\end{array}$ & $\begin{array}{c}\text { Relative } \\
\text { empirical } \\
\mathrm{SE}(N ; \%)\end{array}$ & $\begin{array}{l}\text { Percent } \\
\text { relative } \\
\text { bias }(N)\end{array}$ & $\begin{array}{c}\text { Percent } \\
\text { coverage } \\
(N)\end{array}$ \\
\hline \multicolumn{10}{|c|}{ True population size: 200} \\
\hline 0.5 & 0.1 & 0.1 & 200 & 6.3 & 3.2 & 6.7 & 3.3 & 0.1 & 91 \\
\hline 0.5 & 0.1 & 0.9 & 151 & 8.0 & 5.3 & 10.5 & 7.0 & -24.6 & 2 \\
\hline 0.5 & 0.2 & 0.1 & 200 & 8.1 & 4.0 & 7.7 & 3.9 & 0.0 & 94 \\
\hline 0.5 & 0.2 & 0.9 & 120 & 11.3 & 9.4 & 12.7 & 10.6 & -40.1 & 0 \\
\hline 0.2 & 0.1 & 0.1 & 200 & 40.4 & 20.2 & 36.5 & 18.3 & -0.2 & 95 \\
\hline 0.2 & 0.1 & 0.9 & 144 & 39.6 & 27.4 & 38.1 & 26.4 & -27.8 & 54 \\
\hline 0.2 & 0.2 & 0.1 & 199 & 47.9 & 24.1 & 43.2 & 21.7 & -0.5 & 92 \\
\hline 0.2 & 0.2 & 0.9 & 113 & 55.7 & 49.5 & 44.4 & 39.5 & -43.7 & 35 \\
\hline 0.1 & 0.1 & 0.1 & 192 & 137.2 & 71.5 & 95.1 & 49.5 & -4.1 & 83 \\
\hline 0.1 & 0.1 & 0.9 & 133 & 137.8 & 103.7 & 87.5 & 65.8 & -33.5 & 55 \\
\hline 0.1 & 0.2 & 0.1 & 198 & 177.7 & 89.7 & 114.0 & 57.5 & -0.9 & 84 \\
\hline 0.1 & 0.2 & 0.9 & 98 & 97.7 & 99.5 & 84.0 & 85.6 & -50.9 & 35 \\
\hline \multicolumn{10}{|c|}{ True population size: 100} \\
\hline 0.5 & 0.1 & 0.1 & 100 & 4.5 & 4.5 & 4.0 & 4.0 & -0.1 & 93 \\
\hline 0.5 & 0.1 & 0.9 & 75 & 5.6 & 7.5 & 7.1 & 9.5 & -24.9 & 10 \\
\hline 0.5 & 0.2 & 0.1 & 100 & 5.8 & 5.8 & 6.1 & 6.1 & -0.1 & 91 \\
\hline 0.5 & 0.2 & 0.9 & 60 & 8.3 & 14.0 & 9.4 & 15.8 & -40.4 & 5 \\
\hline 0.2 & 0.1 & 0.1 & 99 & 36.3 & 36.6 & 33.1 & 33.4 & -0.9 & 88 \\
\hline 0.2 & 0.1 & 0.9 & 70 & 29.7 & 42.6 & 28.5 & 40.8 & -30.2 & 54 \\
\hline 0.2 & 0.2 & 0.1 & 99 & 39.1 & 39.5 & 31.0 & 31.3 & -1.1 & 90 \\
\hline 0.2 & 0.2 & 0.9 & 54 & 40.9 & 76.3 & 29.5 & 55.1 & -46.3 & 43 \\
\hline 0.1 & 0.1 & 0.1 & 89 & 81.5 & 91.4 & 62.2 & 69.8 & -10.9 & 74 \\
\hline 0.1 & 0.1 & 0.9 & 63 & 60.0 & 96.0 & 53.6 & 85.8 & -37.5 & 42 \\
\hline 0.1 & 0.2 & 0.1 & 87 & 80.9 & 93.4 & 61.2 & 70.7 & -13.5 & 65 \\
\hline 0.1 & 0.2 & 0.9 & 35 & 30.8 & 87.8 & 32.1 & 91.6 & -65.0 & 11 \\
\hline
\end{tabular}


TABLE 6.-Extended.

\begin{tabular}{|c|c|c|c|}
\hline $\begin{array}{l}\text { Capture } \\
\text { probability }\end{array}$ & $\begin{array}{l}\text { Average } \\
\text { estimated } \\
\text { survival } \\
\text { probability } \\
\text { (PHI) }\end{array}$ & $\begin{array}{l}\text { Average } \\
\text { analytical } \\
\text { SE(PHI) }\end{array}$ & $\begin{array}{l}\text { Empirical } \\
\text { SE(PHI) }\end{array}$ \\
\hline \multicolumn{4}{|c|}{ True population size: 200} \\
\hline 0.5 & 1.00 & 0.023 & 0.022 \\
\hline 0.5 & 1.00 & 0.031 & 0.030 \\
\hline 0.5 & 1.00 & 0.042 & 0.043 \\
\hline 0.2 & 1.00 & 0.164 & 0.143 \\
\hline 0.2 & 1.01 & 0.194 & 0.181 \\
\hline 0.2 & 1.01 & 0.237 & 0.218 \\
\hline 0.1 & 1.06 & 0.548 & 0.426 \\
\hline 0.1 & 1.08 & 0.618 & 0.549 \\
\hline 0.1 & 1.06 & 0.737 & 0.677 \\
\hline \multicolumn{4}{|c|}{ True population size: 100} \\
\hline 0.5 & 1.00 & 0.032 & 0.033 \\
\hline 0.5 & 1.00 & 0.044 & 0.042 \\
\hline 0.5 & 1.00 & 0.060 & 0.056 \\
\hline 0.2 & 1.00 & 0.242 & 0.213 \\
\hline 0.2 & 1.02 & 0.306 & 0.277 \\
\hline 0.2 & 1.01 & 0.373 & 0.311 \\
\hline 0.1 & 1.08 & 0.826 & 0.548 \\
\hline 0.1 & 1.08 & 0.883 & 0.697 \\
\hline 0.1 & 1.12 & 1.026 & 0.753 \\
\hline
\end{tabular}

TABLE 7.-Extended.

\begin{tabular}{|c|c|c|c|}
\hline $\begin{array}{c}\text { Capture } \\
\text { probability }\end{array}$ & $\begin{array}{c}\text { Average } \\
\text { estimated } \\
\text { survival } \\
\text { probability } \\
(\mathrm{PHI})\end{array}$ & $\begin{array}{c}\text { Average } \\
\text { analytical } \\
\text { SE(PHI) }\end{array}$ & $\begin{array}{l}\text { Empirical } \\
\text { SE(PHI) }\end{array}$ \\
\hline \multicolumn{4}{|c|}{ True population size: 200} \\
\hline 0.5 & 1.00 & 0.031 & 0.030 \\
\hline 0.5 & 0.93 & 0.062 & 0.057 \\
\hline 0.5 & 1.01 & 0.040 & 0.040 \\
\hline 0.5 & 0.90 & 0.108 & 0.101 \\
\hline 0.2 & 1.00 & 0.193 & 0.191 \\
\hline 0.2 & 0.96 & 0.272 & 0.241 \\
\hline 0.2 & 1.00 & 0.220 & 0.197 \\
\hline 0.2 & 0.91 & 0.440 & 0.329 \\
\hline 0.1 & 1.08 & 0.706 & 0.483 \\
\hline 0.1 & 1.02 & 0.789 & 0.551 \\
\hline 0.1 & 1.08 & 0.773 & 0.566 \\
\hline 0.1 & 0.97 & 0.852 & 0.688 \\
\hline \multicolumn{4}{|c|}{ True population size: 100} \\
\hline 0.5 & 1.00 & 0.044 & 0.046 \\
\hline 0.5 & 0.95 & 0.089 & 0.073 \\
\hline 0.5 & 1.01 & 0.057 & 0.059 \\
\hline 0.5 & 0.91 & 0.159 & 0.143 \\
\hline 0.2 & 1.00 & 0.289 & 0.246 \\
\hline 0.2 & 1.01 & 0.440 & 0.372 \\
\hline 0.2 & 1.03 & 0.385 & 0.338 \\
\hline 0.2 & 0.97 & 0.667 & 0.535 \\
\hline 0.1 & 1.10 & 0.894 & 0.678 \\
\hline 0.1 & 1.02 & 0.920 & 0.670 \\
\hline 0.1 & 1.08 & 0.909 & 0.690 \\
\hline 0.1 & 0.94 & 0.925 & 0.694 \\
\hline
\end{tabular}

population size would be to increase the capture probability. Our simulation results showed that a high capture probability $(p=0.50)$ improved the quality of estimates in general, even when temporary emigration occurred. Unfortunately, high capture probabilities are difficult to obtain in field studies, and the level of sampling needed may be inappropriate for a threatened species.

\section{Recommendations}

Although we captured 293 Gulf sturgeon from 1982 to 1991 , tag loss caused the count of individual fish captured to be an unreliable indicator of population size. During the 10-year period, several fish were captured with scars from shed Monel or Floy tags; however, those fish could not be uniquely identified as recaptures. In most of the early years of the study, fish were marked with only two Floy tags and one Monel tag. In our 1993 study, we found that Gulf sturgeon shed Floy tags in as little as 2 weeks, so we recommend that internal PIT tags be used in addition to external tags to uniquely mark fish in all future Gulf sturgeon sampling programs. Higher retention rates have been reported for PIT tags than for several external tags with shortnose sturgeon Acipenser brevirostrum, Atlantic sturgeon, and Gulf sturgeon (Smith et al. 1990; Clugston 1996).

Our telemetry study showed that some Gulf sturgeon that were initially found at the dam left during the study, so sampling only at the JWLD probably produced an underestimate of population size for the entire river. Fish that migrated downstream may have moved to other areas that also contained significant numbers of Gulf sturgeon. To estimate the population in the entire river downstream of the JWLD, all significant concentration areas would need to be located (possibly using telemetry) and sampled. Radio-tagged fish can be used as the marked fish within any one sampling area and can provide information about both permanent and temporary emigration (Pollock et al. 1990; White and Garrott 1990). Although costly, this approach would allow a two-sample capture-recapture experiment to be performed within each sampling area. Population size would then be determined by adding the estimates from the different concentration areas.

Because of the low estimated abundance of Gulf sturgeon in the Apalachicola River below the JWLD, we recommend continued monitoring of this population with standardized gillnetting. Sampling should be standardized in terms of the number of nets and mesh sizes used so that future 
capture-recapture analyses will be less biased and so that catch per unit effort can be used as an index of abundance. An interval of 3-5 years between surveys may be adequate to detect long-term trends in abundance. The surveys would also provide additional length composition data that can be used to test our hypothesis that good recruitment occurs infrequently in this population.

\section{Acknowledgments}

This work was made possible by funding from the U.S. Fish and Wildlife Service (FWS). We thank Gail Carmody, Laura Jenkins, Pledger Moon, Frank Parauka, Chuck Reynolds, and the entire FWS Panama City Field Office staff for their help in the field and office. We thank Charles Wooley for assistance in interpreting the 1983 survey data, and John Odenkirk for allowing us to present his 1987 summer telemetry results. We also thank Gail Carmody, Jim Clugston, and Frank Parauka for comments on an earlier version of this manuscript.

\section{References}

Arnason, A. N., and L. Baniuk. 1978. POPAN-2: a data maintenance and analysis system for mark-recapture data. Charles Babbage Research Centre, St. Pierre, Manitoba.

Arnason, A. N., and K. H. Mills. 1981. Bias and loss of precision due to tag loss in Jolly-Seber estimates for mark-recapture experiments. Canadian Journal of Fisheries and Aquatic Sciences 38:1077-1095.

Balser, J. P. 1981. Confidence interval estimation and tests for temporary outmigration in tag-recapture studies. Doctoral dissertation. Cornell University, Ithaca, New York.

Barkuloo, J. M. 1987. Striped bass and sturgeon research on the Apalachicola River: implications for population recovery. U.S. Fish and Wildlife Service, Panama City, Florida.

Barkuloo, J. M. 1988. Report on the conservation of the Gulf of Mexico sturgeon, Acipenser oxyrhynchus desotoi. U.S. Fish and Wildlife Service, Panama City, Florida.

Bass, D. G., and D. T. Cox. 1985. River habitat and fishery resources of Florida. Pages 121-187 in W. Seaman, Jr., editor. Florida aquatic habitat and fishery resources. American Fisheries Society, Florida Chapter, Eustis.

Carr, S. H., F. Tatman, and F. A. Chapman. 1996. Observations on the natural history of the Gulf of Mexico sturgeon (Acipenser oxyrinchus de sotoi Vladykov 1955) in the Suwannee River, southeastern United States. Ecology of Freshwater Fish 1996: 169-174.

Clugston, J. P. 1996. Retention of T-bar anchor tags and passive integrated transponder tags by Gulf sturgeon. North American Journal of Fisheries Management 16:682-685.
Clugston, J. P., A. M. Foster, and S. H. Carr. 1995. Gulf sturgeon, Acipenser oxyrinchus desotoi, in the Suwannee River, Florida, USA. Pages 215-224 in A. D. Gershanovich and T. I. J. Smith, editors. Proceedings of the International Symposium on Sturgeons. VNIRO Publishing, Moscow.

Foster, A. M., and J. P. Clugston. 1997. Seasonal migration of Gulf sturgeon in the Suwannee River, Florida. Transactions of the American Fisheries Society $126: 302-308$.

Gilbert, C. R. 1992. Atlantic sturgeon. Pages 31-39 in R.A. Ashton, editor. Rare and endangered biota of Florida, volume II, fishes. University Press of Florida, Gainesville.

Gilbert, R. O. 1973. Approximations of the bias in the Jolly-Seber capture-recapture model. Biometrics 29:501-526.

Huff, J. A. 1975. Life history of the Gulf of Mexico sturgeon, Acipenser oxyrhynchus desotoi, in the Suwannee River, Florida. Florida Department of Natural Resources, Marine Resources Publication 16, St. Petersburg.

Jolly, G. M. 1965. Explicit estimates from capture-recapture data with both death and immigration-stochastic model. Biometrika 52:225-247.

Kendall, W. L., and J. D. Nichols. 1995. On the use of secondary capture-recapture samples to estimate temporary emigration and breeding proportions. Journal of Applied Statistics 22:751-762.

Kendall, W. L., J. D. Nichols, and J. E. Hines. 1997. Estimating temporary emigration using capture-recapture data with Pollock's robust design. Ecology 78:563-578.

Odenkirk, J. S. 1991. Movements of Gulf of Mexico sturgeon in the Apalachicola River, Florida. Proceedings of the Annual Conference Southeastern Association of Fish and Wildlife Agencies 43(1989):230-238.

Otis, D. L., K. P. Burnham, G. C. White, and D. R. Anderson. 1978. Statistical inference from capture data on closed animal populations. Wildlife Monographs 62 .

Pollock, K. H. 1982. A capture-recapture design robust to unequal probability of capture. Journal of Wildlife Management 46:757-760.

Pollock, K. H., J. D. Nichols, C. Brownie, and J. E. Hines. 1990. Statistical inference for capture-recapture experiments. Wildlife Monographs 107.

Reynolds, C. R. 1993. Gulf sturgeon sightings: a summary of public responses. U.S. Fish and Wildlife Service, Publication PCFO-FR 93-01, Panama City, Florida.

Ricker, W. E. 1975. Computation and interpretation of biological statistics of fish populations. Fisheries Research Board of Canada Bulletin 191.

Schnabel, Z. E. 1938. The estimation of the total fish population of a lake. American Mathematical Monthly 45:348-352.

Seber, G. A. F. 1965. A note on the multiple-recapture census. Biometrika 52:249-259.

Smith, T. I. J., S. D. Lamprecht, and J. W. Hall. 1990. Evaluation of tagging techniques for shortnose stur- 
geon and Atlantic sturgeon. Pages 134-141 in N. C. Parker and five coeditors. Fish-marking techniques. American Fisheries Society, Symposium 7, Bethesda, Maryland.

U.S. Commission of Fish and Fisheries. 1902. Report of the Commissioner for the year ending June 30, 1901, Part XXVII. U.S. Government Printing Office, Washington, D.C.

U.S. Fish and Wildlife Service and Gulf States Marine Fisheries Commission. 1995. Gulf sturgeon recovery plan. U.S. Fish and Wildlife Service and Gulf States Marine Fisheries Commission, Atlanta.

Vladykov, V. D. 1955. A comparison of Atlantic sea sturgeon with a new subspecies from the Gulf of Mexico (Acipenser oxyrhynchus desotoi). Journal of the Fisheries Research Board of Canada 12:754761.

White, G. C., D. R. Anderson, K. P. Burnham, and D. L. Otis. 1982. Capture-recapture and removal methods for sampling closed populations. Los Al- amos National Laboratory, LA 8787-NERP, Los Alamos, New Mexico.

White, G. C., and R. A. Garrott. 1990. Analysis of wildlife radio-tracking data. Academic Press, San Diego, California.

Wooley, C. M. 1985. Evaluation of morphometric characters used in taxonomic separation of Gulf of Mexico sturgeon, Acipenser oxyrhynchus desotoi. Pages 97-103 in F. Binkowski and S.I. Doroshov, editors. North American sturgeon: developments in environmental biology of fishes, volume 6. Dr. W. Junk, Dordrecht, Netherlands.

Wooley, C. M., and E. J. Crateau. 1982. Observations of Gulf of Mexico sturgeon (Acipenser oxyrhynchus desotoi) in the Apalachicola River, Florida. Florida Scientist 45:244-248.

Wooley, C. M., and E. J. Crateau. 1985. Movement, microhabitat, exploitation, and management of Gulf of Mexico sturgeon, Apalachicola River, Florida. North American Journal of Fisheries Management 5:590-605. 